\title{
Selective Synthesis of the Aminobutadiene Intermediate and Mechanistic Analysis of 1,4-Dihydropyridine Formation Reaction in Water
}

\author{
Shigeki Isomura, ${ }^{a}$ Miyu Watanabe, ${ }^{a}$ Ayano Suzuki, ${ }^{a}$ Yoshinori Okuno, ${ }^{a}$ Misaki Okayasu, ${ }^{b}$ \\ Isao Azumaya, ${ }^{b}$ and Yasuo Sato*,a \\ ${ }^{a}$ Department of Medicinal Chemistry, Yokohama University of Pharmacy; 601 Matano-cho, Totsuka-ku, Yokohama \\ 245-0066, Japan: and ${ }^{b}$ Chemical Manufacturing Science, Faculty of Pharmaceutical Sciences, Toho University; \\ 2-2-1 Miyama, Funabashi, Chiba 274-8510, Japan. \\ Received November 5, 2021; accepted December 21, 2021
}

We previously isolated an aminobutadiene derivative as a by-product in the synthesis of a 1,4-dihydropyridine (1,4-DHP) derivative by the reaction of methyl propiolate with excess ammonium acetate in water, and we proposed that it is an intermediate in the formation of 1,4-DHP. Here, to test this idea and to investigate the reaction mechanism, we selectively synthesized the aminobutadiene derivative in EtOH and examined its reactivity. The yield of the aminobutadiene derivative was increased in the presence of excess ammonium salt. X-Ray crystal structure analysis indicated the presence of an intramolecular hydrogen bond between the terminal amine and ester carbonyl oxygen, together with a short $\mathrm{C}-\mathrm{N}$ bond length consistent with enamine-imine equilibrium. Direct cyclization of the aminobutadiene derivative with methyl propiolate to afford the 1,4-DHP derivative did not proceed well, but the yield was increased in the presence of morpholine salt as an additive. These results suggest that the predominant reaction pathway from the intermediate to 1,4-DHP in water involves Michael addition of a second amine molecule and reaction with methyl propiolate, followed by intramolecular cyclization and elimination of amine.

Key words 1,4-dihydropyridine; water solvent; Michael addition; Diels-Alder type reaction

\section{Introduction}

1,4-Dihydropyridine (1,4-DHP) derivatives are important both in biochemistry and medicinal chemistry. For example, nicotinamide adenine dinucleotide plays a role in many reductive and oxidative biosynthetic reactions, ${ }^{1,2)}$ and 4-phenyl-1,4DHP derivatives with calcium channel-blocking activity are used clinically in the treatment of hypertension or angina. ${ }^{3-5}$ )

We have investigated the synthesis of 1,4-DHP derivatives in water as a solvent, ${ }^{6,7)}$ and obtained 4-acetate-functionalized 1,4-DHP (1) by heating methyl propiolate and excess amount of ammonium acetate in $\mathrm{H}_{2} \mathrm{O}$. However, in this reaction, substituted aminobutadiene 2 was obtained as a by-product (Chart 1). We hypothesized that $\mathbf{2}$ is an intermediate in the formation of 1,4-DHP. Here, we aimed to test this idea by selectively synthesizing $\mathbf{2}$ and examining its conversion to $\mathbf{1}$.

\section{Results and Discussion}

All attempts to obtain $\mathbf{2}$ as the main product in water were unsuccessful. However, the reaction in EtOH gave 2 selectively, though in low yield, under stoichiometric conditions $\left(80^{\circ} \mathrm{C}\right.$ $2 \mathrm{~h}$ ). The use of excess ammonium acetate improved the yield, and 2 was obtained in $63 \%$ yield when 10 equivalent (equiv.) of ammonium acetate was employed. Other organic solvents resulted in lower yields, as compared with EtOH (Table 1).
We next examined 1,4-DHP (1) formation from 2 and 1 equiv. of methyl propiolate in $\mathrm{H}_{2} \mathrm{O}$. In the reaction medium used for 1,4-DHP (1) synthesis from methyl propiolate and ammonium acetate, the formed $\mathbf{2}$ was considered to exist as an acetic acid salt. Therefore, the acetic acid salt of $\mathbf{2}$ was used in this study. As the salt of purified $\mathbf{2}$ exhibited low solubility in water, the reaction was run under more dilute conditions than in our previous study. ${ }^{6}$ Intriguingly, trimethyl 1,3,5-benzenetricarboxylate $\mathbf{3}$ was the major product at various reaction times (Entries $1-3$, Table 2), but addition of 1 equiv. of morpholine acetic acid salt increased the yield of 1 to $46 \%$ (Entry 4, Table 2).

We next examined the formation of $\mathbf{3}$ in the reaction of methyl propiolate and ammonium acetate. With 2 equiv. of ammonium acetate, 3 was isolated in $11 \%$ yield after $2 \mathrm{~h}$. Again, the addition of morpholine salt improved the yield of $\mathbf{1}$ (Entry 3, Table 3).

We previously discussed the mechanism of 1,4-DHP (1) formation in the reaction in water, ${ }^{6}$ and proposed two reaction routes. The first is direct intermolecular cyclization of $\mathbf{2}$ with methyl propiolate, while the second is intramolecular cyclization after second Michael addition of amine to $\mathbf{2}$ and further reaction with methyl propiolate. The results in Table 2 suggest that direct formation of 1,4-DHP does not proceed well under these conditions. X-Ray crystallographic analysis of $\mathbf{2}^{8)}$ (Chart<smiles>C#CC(=O)OC</smiles>

Chart 1. 1,4-Dihydropyridine Synthesis in Water ${ }^{6)}$ 
2) suggested the presence of an intramolecular hydrogen bond between the terminal amine and ester carbonyl oxygen. Also, the short $\mathrm{C}-\mathrm{N}$ single bond length is consistent with an enamine-imine equilibrium. These features would reduce the reactivity of the nitrogen atom of $\mathbf{2}$, and may explain the poor outcome of direct cyclization. The formation of $\mathbf{3}$ was unexpected, but may be due to Diels-Alder type reaction of $\mathbf{2}$ and methyl propiolate ${ }^{9)}$ followed by elimination of ammonia to afford 3. The resulting ammonium acetate would be recycled in the reaction medium. This makes it difficult to quantify the involvement of the direct cyclization path (Chart 3). On the other hand, the use of an added secondary amine salt markedly increased the yield. Thus, we consider that the main route of 1,4-DHP formation in water is intramolecular cyclization after a second Michael addition. Morpholine showed a greater enhancing effect than ammonia, presumably because of its greater nucleophilicity. ${ }^{10)}$

Table 1. Synthesis of $\mathbf{2}$ under Various Conditions

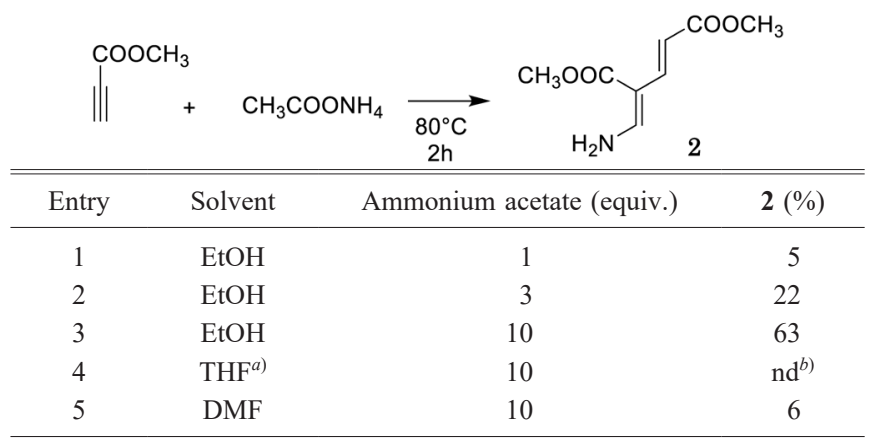

a) Reflux at $66^{\circ} \mathrm{C} . b$ ) Not detected.
In conclusion, the proposed intermediate 2 in the reaction of methyl propiolate with excess ammonium acetate in water to afford 1,4-DHP derivative 1 was selectively synthesized by using methyl propiolate and excess ammonium acetate in $\mathrm{EtOH}$. We found that intermolecular direct cyclization of $\mathbf{2}$ and methyl propiolate to afford $\mathbf{1}$ did not proceed well. Instead, a different type of cyclization occurred to afford trimethyl 1,3,5-benzenetricarboxylate $\mathbf{3}$ as the major product. However, addition of morpholine acetic acid salt markedly increased the yield of $\mathbf{1}$. We concluded that Michael reaction of additional amine, methyl propiolate and $\mathbf{2}$, followed by intramolecular cyclization and elimination of amine, is the major pathway leading to the formation of 1,4-DHP in water. This is a significant finding, because chemical reactions in aqueous media show unique features, and are environmentally benign and cost effective. ${ }^{11-14)}$ Further studies on this reaction are underway.

\section{Experimental}

General Methods ${ }^{1} \mathrm{H}-\mathrm{NMR}$ spectra were recorded on a $500 \mathrm{MHz}$ NMR spectrometer (JEOL ECA500) in $\mathrm{CDCl}_{3}$ unless otherwise noted. MS were obtained on a JEOL JMS-700 MStation at Kitasato University, using chemical ionization or electron impact techniques. IR spectra were obtained on a PerkinElmer, Inc. Spectrum 100 FT-IR spectrometer. TLC bands were visualized under UV light $(254 \mathrm{~nm})$ or by spraying the plate with a solution of phosphomolybdic acid followed by heating until color developed.

4-Aminomethylene-pent-2-enedioic Acid Dimethyl Ester (2) Methyl propiolate $(126 \mathrm{mg}, 1.5 \mathrm{mmol})$ and ammonium acetate $(1.15 \mathrm{~g}, 15 \mathrm{mmol})$ were dissolved in $\mathrm{EtOH}(10 \mathrm{~mL})$. The reaction mixture was heated at $80^{\circ} \mathrm{C}$ for $2 \mathrm{~h}$. After cooling, the

Table 2. 1,4-DHP (1) Synthesis from 2 and Methyl Propiolate<smiles>C#CC(=O)OCC(=O)OCC(=O)OCC(=O)OCC(=O)OC</smiles>

\begin{tabular}{cccccc}
\hline \hline Entry & Time $(\mathrm{h})$ & $\mathbf{1}(\%)$ & $\mathbf{3}(\%)$ & Recovery of $\mathbf{2}(\%)$ & Additive \\
\hline 1 & 1 & 10 & 13 & 44 & \\
2 & 2 & 15 & 20 & 8 & Morpholine/AcOH (1 equiv.) \\
3 & 4 & 21 & 32 & 12 & . \\
4 & 2 & 46 & 25 & 12 & \\
\hline
\end{tabular}

Table 3. Formation of $\mathbf{1}$ and $\mathbf{3}$ from Methyl Propiolate and Ammonium Acetate

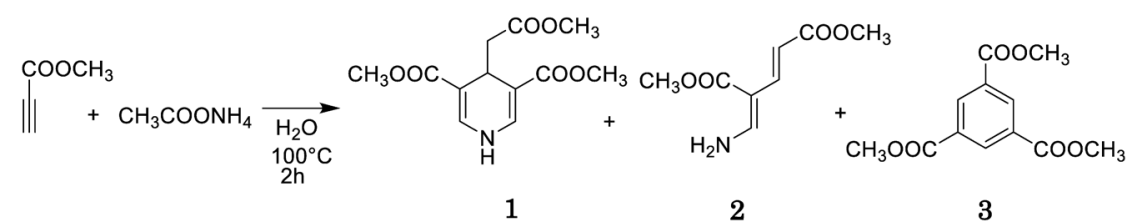

\begin{tabular}{cccccc} 
& & $\mathbf{1}$ & $\mathbf{2}$ & $\mathbf{3}$ \\
\hline \hline Entry & $\begin{array}{c}\text { Ammonium acetate } \\
\text { (equiv.) }\end{array}$ & $\mathbf{1}(\%)$ & $\mathbf{2}(\%)$ & $\mathbf{3}(\%)$ & Additive \\
\hline 1 & 0.33 & 6 & 4 & $\mathrm{nd}^{a}$ & 11 \\
2 & 2 & 21 & 12 & 19 & Morpholine/AcOH (0.33 equiv.) \\
3 & 2 & 63 & 8 & & \\
\hline
\end{tabular}

a) Not detected. 
mixture was concentrated and extracted with AcOEt $(30 \mathrm{~mL})$. The organic layer was washed with sat. $\mathrm{NaHCO}_{3}$ aq $(15 \mathrm{~mL})$ and water $(15 \mathrm{~mL})$. The organic layer was dried over $\mathrm{MgSO}_{4}$ and concentrated in vacuo. Purification of crude product by silica gel column chromatography (AcOEt: $n$-hexane $=1: 1$ ) and recrystallization (AcOEt: $n$-hexane $=1: 3$ ) gave $87 \mathrm{mg}$ (63\%, white plates) of 2 .

mp $134-135^{\circ} \mathrm{C}$; MS (EI) $185\left(\mathrm{M}^{+}\right)$; ${ }^{1} \mathrm{H}-\mathrm{NMR} \quad\left(\mathrm{CDCl}_{3}\right)$ $\delta$ : $3.66(3 \mathrm{H}, \mathrm{s}), 3.78(3 \mathrm{H}, \mathrm{s}), 5.50(2 \mathrm{H}$, broad $\mathrm{s}), 6.12(1 \mathrm{H}$, d, $J=15 \mathrm{~Hz}), 7.25-7.40(1 \mathrm{H}, \mathrm{m}), 7.38(1 \mathrm{H}, \mathrm{d}, J=15 \mathrm{~Hz})$; ${ }^{13} \mathrm{C}-\mathrm{NMR}\left(\mathrm{CDCl}_{3}\right) \delta: 51.0(\mathrm{~s}), 51.2(\mathrm{~s}), 97.2(\mathrm{~s}), 109.5(\mathrm{~s}), 143.3(\mathrm{~s})$, 154.5(s), 169.1(s); IR (neat) $\mathrm{cm}^{-1}: 3380,3246,2948,1649,1583$, 1435, 1330; Anal. Calcd for $\mathrm{C}_{8} \mathrm{H}_{11} \mathrm{NO}_{4} / 0.1 \mathrm{H}_{2} \mathrm{O}$ (186.98): C, 51.39; H, 6.03; N, 7.49. Found: C, 51.58; H, 5.94; N, 7.57.

Synthesis of 1 and 3 (from 2 and Methyl Propiolate) 2 $(100 \mathrm{mg}, 0.54 \mathrm{mmol})$ and acetic acid $(33 \mathrm{mg}, 0.54 \mathrm{mmol})$ were dissolved in $\mathrm{MeOH}(2 \mathrm{~mL})$, and the solution was evaporated. To the residue, water $(2 \mathrm{~mL})$ and methyl propiolate $(45 \mathrm{mg}$, $0.54 \mathrm{mmol}$ ) were added. The reaction mixture was heated at

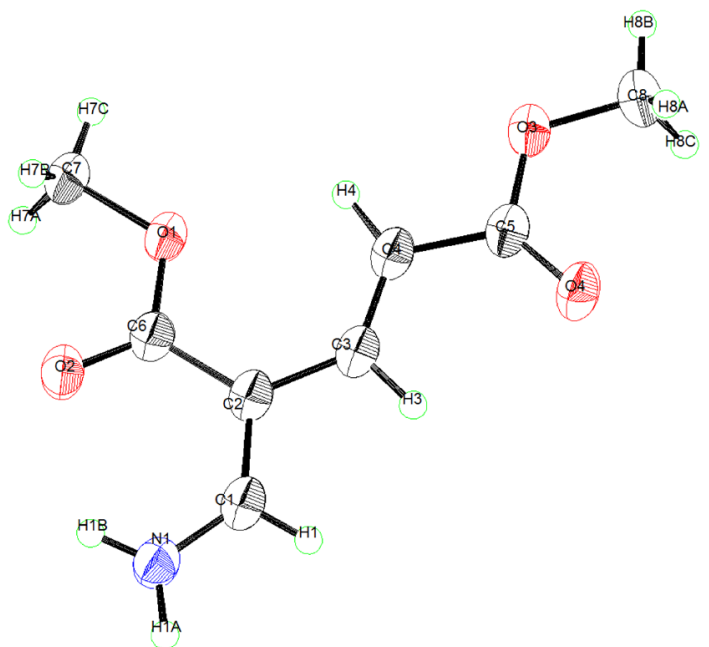

Chart 2. ORTEP Drawing of the Structure of 2 Determined by X-Ray Crystallographic Analysis $100^{\circ} \mathrm{C}$ for $2 \mathrm{~h}$. After cooling, the mixture was extracted with AcOEt $(15 \mathrm{~mL})$ and sat. $\mathrm{NaHCO}_{3}$ aq $(10 \mathrm{~mL})$. The organic layer was washed with water $(10 \mathrm{~mL})$, then dried over $\mathrm{MgSO}_{4}$ and concentrated in vacuo. Purification of the crude product by silica gel column chromatography (AcOEt: $n$-hexane $=1: 1$ ) gave $22 \mathrm{mg}(15 \%)$ of $\mathbf{1}, 27 \mathrm{mg}(20 \%)$ of 3 and $16 \mathrm{mg}(16 \%$ recovery) of 2 .

4-Methoxycarbonylmethyl-1,4-dihydropyridine-3,5dicarboxylic Acid Dimethyl Ester (1) Slightly yellow needles, mp $113-114{ }^{\circ} \mathrm{C}$; MS (EI) $269\left(\mathrm{M}^{+}\right)$; ${ }^{1} \mathrm{H}-\mathrm{NMR}\left(\mathrm{CDCl}_{3}\right)$ $\delta: 2.51(2 \mathrm{H}, \mathrm{d}, J=5 \mathrm{~Hz}), 3.61(3 \mathrm{H}, \mathrm{s}), 3.74(6 \mathrm{H}, \mathrm{s}), 4.21(1 \mathrm{H}, \mathrm{t}$, $J=5 \mathrm{~Hz}), 7.29(2 \mathrm{H}, \mathrm{d}, J=5 \mathrm{~Hz}) ;{ }^{13} \mathrm{C}-\mathrm{NMR}\left(\mathrm{CDCl}_{3}\right) \delta: 29.6(\mathrm{~s})$, 40.4(s), 51.5(s), 105.8(s), 135.6(s), 167.3(s), 172.3(s); IR (neat) $\mathrm{cm}^{-1}$ : 3285, 1724, 1666, 1602, 1505, 1433, 1325; Anal. Calcd for $\mathrm{C}_{12} \mathrm{H}_{15} \mathrm{NO}_{6}$ (269.25): C, 53.53; H, 5.62; N, 5.20. Found: C, 53.25; H, 5.67; N, 5.15.

Trimethyl 1,3,5-Benzenetricarboxylate (3) Colorless needles, mp $162.5-163{ }^{\circ} \mathrm{C}$; MS (EI) $252\left(\mathrm{M}^{+}\right)$; ${ }^{1} \mathrm{H}-\mathrm{NMR}$ $\left(\mathrm{CDCl}_{3}\right) \delta: 3.98(6 \mathrm{H}, \mathrm{s}), 8.86(3 \mathrm{H}, \mathrm{s}) ;{ }^{13} \mathrm{C}-\mathrm{NMR}\left(\mathrm{CDCl}_{3}\right) \delta$ : 52.6(s), 131.2(s), 134.6(s), 165.4(s); IR (neat) $\mathrm{cm}^{-1}:$ 2957, 1721, 1431, 1342, 1237; Anal. Calcd for $\mathrm{C}_{12} \mathrm{H}_{12} \mathrm{O}_{6}$ (252.23): C, 57.14; H, 4.80. Found: C, 57.25; H, 4.87.

Synthesis of 1 and 3 (from Ammonium Acetate and Methyl Propiolate in the Presence of Morpholine Acetic Acid Salt) Methyl propiolate $(136 \mathrm{mg}, 1.62 \mathrm{mmol})$ and ammonium acetate $(248 \mathrm{mg}, 3.24 \mathrm{mmol})$ were dissolved in water $(2 \mathrm{~mL})$. To this solution were added morpholine $(48 \mathrm{mg}, 0.54 \mathrm{mmol})$ and acetic acid $(32 \mathrm{mg}, 0.54 \mathrm{mmol})$. The reaction mixture was heated at $100^{\circ} \mathrm{C}$ for $2 \mathrm{~h}$. After cooling, the mixture was extracted with AcOEt $(15 \mathrm{~mL})$ and sat. $\mathrm{NaHCO}_{3}$ aq $(10 \mathrm{~mL})$. The organic layer was washed with water $(10 \mathrm{~mL})$. The organic layer was dried over $\mathrm{MgSO}_{4}$ and concentrated in vacuo. Purification of the crude product by silica gel column chromatography (AcOEt: $n$-hexane $=1: 1)$ gave $92 \mathrm{mg}(63 \%)$ of 1, $26 \mathrm{mg}(19 \%)$ of $\mathbf{3}$, and $8 \mathrm{mg}(8 \%)$ of $\mathbf{2}$.

Acknowledgments This paper is dedicated to Emeritus Professor Koichi Shudo, who passed away on 7th July 2021.

We are grateful to Dr. K. Nagai of the School of Pharma-

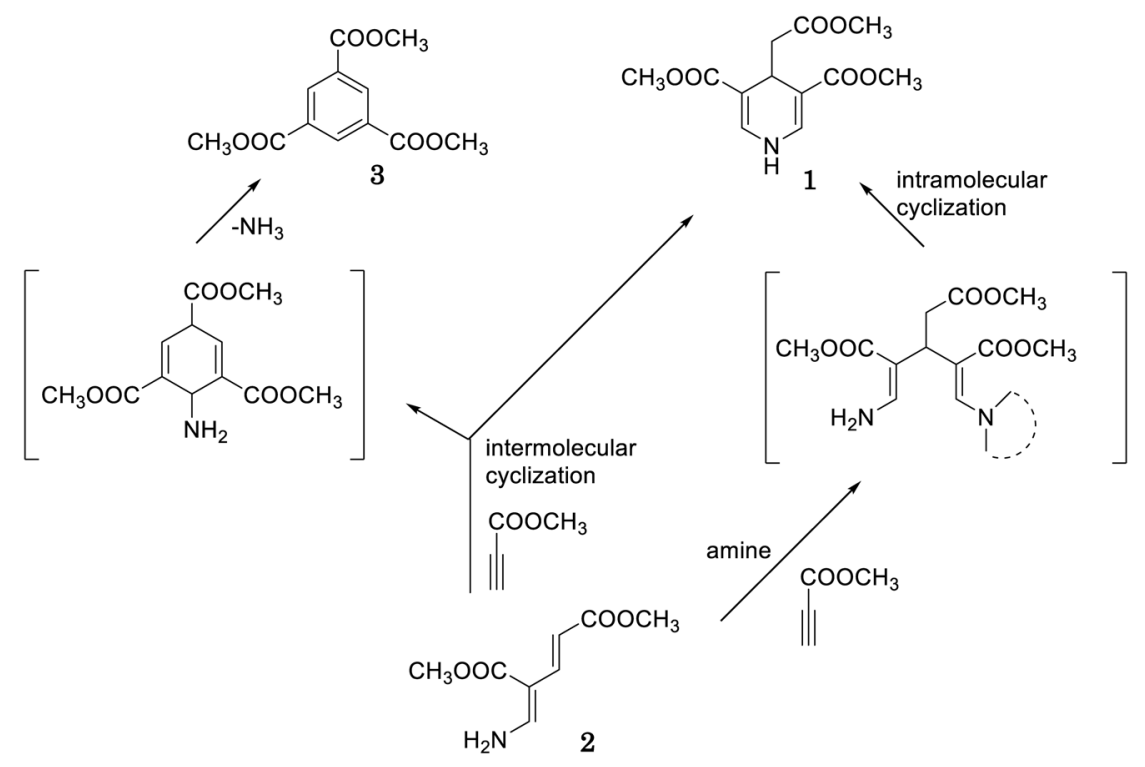


ceutical Sciences, Kitasato University, for the MS spectra and elemental analysis. This research was supported by Yokohama University of Pharmacy.

Conflict of Interest The authors declare no conflict of interest.

Supplementary Materials This article contains supplementary materials. The supplementary materials contain ${ }^{1} \mathrm{H}-$ and ${ }^{13} \mathrm{C}$-NMR spectra of $\mathbf{1}-\mathbf{3}$, and X-ray crystallographic data of 2 .

\section{References and Notes}

1) Eisner U., Kuthan J., Chem. Rev., 72, 1-42 (1972). 2) Ying W., Antioxid. Redox Signal., 10, 179-206 (2008).

3) Campbell K. P., Leung A. T., Sharp A. H., Trends Neurosci., 11, 425-430 (1988).

4) Triggle D. J., Biochem. Pharmacol., 74, 1-9 (2007).

5) Shaldam M. A., El-Hamamsy M. H., Saleh D. O., El-Moselhy T. F.,
Chem. Pharm. Bull., 64, 297-304 (2016).

6) Isomura S., Horigome A., Kubo K., Yoshizawa Y., Okuno Y., Okayasu M., Azumaya I., Sato Y., ChemistrySelect, 3, 3003-3005 (2018).

7) Isomura S., Anzai M., Kobayashi C., Okuno Y., Miyamoto K., Uchiyama M., Sato Y., ChemistrySelect, 5, 2075-2077 (2020).

8) See the supplementary materials for the crystallographic analysis data.

9) Otto S., Engberts J. B. F. N., Pure Appl. Chem., 72, 1365-1372 (2000).

10) Brotzel F., Chu Y. C., Mayr H., J. Org. Chem., 72, 3679-3688 (2007).

11) Hikawa H., Ichinose R., Kikkawa S., Azumaya I., Green Chem., 20, $1297-1305$ (2018)

12) Hikawa H., Imamura H., Kikkawa S., Azumaya I., Green Chem., 20, 3044-3049 (2018).

13) Hayashi A., Ichimaru Y., Sugiura K., Maeda A., Harada Y., Kojima Y., Nakayama K., Imai M., Chem. Pharm. Bull., 69, 581-584 (2021).

14) Kusaka R., Nihonyanagi S., Tahara T., Nat. Chem., 13, 306-311 (2021). 